\title{
Entre el comercio y la política: la trayectoria de Tomás Manuel Anchorena desde la Revolución de Mayo hasta su intervención en la Sala de Representantes de Buenos Aires
}

\author{
Between commerce and politics: the trajectory of Tomás Manuel Anchorena from the May Revolution until his \\ intervention in the Buenos Aires Representatives Hall
}

Diego Ariel Fracchia

Universidad Nacional de Tres de Febrero, Argentina

da.fracchia@gmail.com

\section{ReSUMEN:}

Este artículo explora la trayectoria de Tomás Manuel Anchorena desde 1810 hasta su participación en la Sala de Representantes de Buenos Aires en 1820. El derrotero de este acaudalado comerciante muestra cómo, en un marco de profunda politización de las distintas capas sociales, fue vinculándose paulatinamente con el poder político a pesar de sus cautelas. En este marco, se repasa su aceptación del cargo de Secretario del general Belgrano durante su estadía en el norte y su participación en el Congreso de Tucumán como diputado por Buenos Aires, sobre la que se indaga respecto de su abierta oposición al proyecto de una monarquía incaica. Asimismo, se analiza minuciosamente su actuación como representante en la Sala durante los primeros meses de 1820 , siendo parte del primer elenco que integró dicha institución. Tras ser vetado y puesto en prisión por el Gobernador Sarratea, Anchorena retomó la disputa política, en este caso, defendiéndose públicamente a través de un escrito. Este trabajo se inscribe en una perspectiva historiográfica cuyo objetivo es resaltar las individualidades dentro de procesos más generales. Por ello, a la vez que se expone el recorrido de este actor, se toman en cuenta sus vínculos familiares, comerciales y políticos, enmarcados en los procesos que los afectaron.

Palabras Clave: Tomás Manuel Anchorena, Trayectoria, Política, Sala de Representantes, Buenos Aires, 1810-1820.

\section{Abstract:}

This article explores the trajectory of Tomás Manuel Anchorena from 1810 until his participation in the Hall of Representatives of Buenos Aires in 1820. The course of this wealthy merchant shows how, in a framework of deep politicization of the different social layers, he gradually linked with political power despite its precautions. In this context, his acceptance of the position of Secretary of General Belgrano during his stay in the north and his participation in the Congress of Tucumán as a deputy for Buenos Aires, on which he inquires regarding his open opposition to the project of a monarchy is reviewed Inca. Likewise, his performance as a representative in the Chamber during the first months of 1820 is analyzed thoroughly, being part of the first cast that integrated said institution. After being banned and put in prison by Governor Sarratea, Anchorena resumed the political dispute, in this case, defending himself publicly through a letter. This work is part of a historiographic perspective whose objective is to highlight individualities within more general processes. Therefore, while exposing the route of this actor, their family, commercial and political ties, framed in the processes that affected them, are taken into account.

Keywords: Tomás Manuel Anchorena, Trajectory, Politics, Hall of Representatives, Buenos Aires, 1810-1820.

\section{INTRODUCCIÓN}

La disolución, en 1820, del endeble orden que la Revolución había creado ha sido estudiada largamente, tanto por la historiografía tradicional como por la "nueva historia política". Desde este ámbito, se ha recurrido a los años anteriores (sobre todo lo ocurrido entre 1815 y 1820) para explicar dicho proceso. Así, ese segundo lustro revolucionario ha sido caracterizado como la progresiva cristalización de "dos sistemas 
políticos rivales" cuya expresión más evidente habría sido la batalla de Cepeda en febrero de 1820. En ese marco, el "bando artiguista" y el "directorial" llegaban al enfrentamiento que marcaba, tanto el derrumbe del Gobierno central, como la disolución hacia el interior de esos dos grupos (Halperin Donghi, 2005, p.316). En Buenos Aires, las exigencias planteadas por los vencedores para pactar la paz provocaron la intervención política de miembros de la élite porteña que decidieron ocupar el lugar del gobierno disuelto. Ante el fracaso de la facción centralista, y frente al peligro que implicaba dejar el gobierno en manos de la oposición federalista-popular, algunos miembros de la élite encontraban un nuevo espacio desde donde actuar en un contexto de crisis política acuciante: la Sala de Representantes (Halperin Donghi, 2005, p. 208). Si bien esta institución emergió con el objetivo de elegir un gobernador capaz de pactar la paz con las fuerzas litoraleñas, terminó ese año ocupando "el centro de la escena política provincial" (Ternavasio, 2002, p. 59).

Respecto de los integrantes de la Sala, la historiografía abreva en caracterizaciones de conjunto apuntaladas por interpretaciones que realzan sus procedencias sociales o políticas (Levene, 1932; Halperin Donghi, 2005; Ternavasio, 2002; Herrero, 1999; Di Meglio, 2003). Como complemento, proponemos un estudio pormenorizado de esos actores ya que nos permitiría rastrear las variadas trayectorias y vinculaciones políticas que profundizan y problematizan aquellas imágenes. En este trabajo, nos interesa indagar el recorrido de una figura cuyo derrotero permite mostrar que las experiencias previas, no solo existieron, sino que fueron valiosas herramientas para actuar en el nuevo contexto. Este personaje, portador de un apellido típico de la élite porteña ligada al comercio y a los negocios agropecuarios, fue estudiado principalmente desde una perspectiva socio-económica (Carretero, 1970; Hora, 2006). Sin desconocer esos aportes, nos resulta sugerente hacerlos entrar en diálogo con una dimensión poco abordada hasta ahora: el registro íntimo, político y discursivo a través del análisis de su itinerario durante la década de 1810 hasta su intervención como miembro de la Sala de Representantes. ${ }^{1}$

Para llevar a cabo dicho objetivo, tomamos en consideración las nuevas perspectivas historiográficas que destacan la importancia de estas exploraciones como terreno de un análisis fructífero e ineludible. En este sentido, Pierre Rosanvallon (1997) señala que es necesario recurrir cada vez más a la historia individual de los sujetos, a sus familias, redes, trayectorias y a los procesos que los afectaron. En la misma línea, Pierre Bourdieu (1997, p. 75) sostiene que "cada sistema individual de disposiciones es una variante estructural de los otros, en la que se expresa la singularidad de su posición en el interior de la clase o grupo y de la trayectoria". Consideramos que en lugar de limitarse a miradas generales, aplicables a todos los casos, "resulta imprescindible desarrollar la capacidad para construir abordajes singulares ante situaciones que son singulares, ubicadas en el marco de procesos sociales, políticos y culturales" (Di Pasquale y Summo, 2015, p. 12). Este trabajo busca entonces repensar el recorrido de Tomás Manuel de Anchorena recuperando una singularidad que, lejos de mostrar "una personalidad coherente y estable, acciones sin inercia y decisiones $\sin$ incertidumbre” (Levi, 1989, p. 1327), revela sus oscilaciones en un contexto de profunda politización.

\section{Anchorena en el Alto Perú (1811-1815): las desilusiones y la guerra}

Tomás Manuel Anchorena fue el segundo hijo de Juan Esteban de Anchorena y Romana Josefa López de Anaya Ruiz y Gamiz de las Cuevas. Su padre, nativo de Pamplona, llegó en 1751 a Buenos Aires, donde se dedicó al comercio, accediendo a los mercados de la campaña bonaerense, Montevideo, Córdoba, Santa Fe, Paraguay, Santiago de Chile y Potosí. El casamiento, en 1773, con una joven perteneciente a una respetable pero empobrecida familia de Buenos Aires le añadió respetabilidad y decencia a su incipiente fortuna. ${ }^{2}$ Tuvieron siete hijos de los que sobrevivieron tres: Juan José Cristóbal (1780), Tomás Manuel (1783) y Mariano Nicolás (1785) (Cutolo, 1968, T. I, p. 160). En el marco de la creación del consulado de Buenos Aires, Anchorena integró un grupo de 15 comerciantes $^{3}$ para presentar sus solicitudes ante el Virrey y luego, en 1794, al crearse la corporación, fue designado primer cónsul (Milletich, 2006, p. 316). Sus estrategias 
comerciales le permitieron legar a sus descendientes un patrimonio de más de $\$ 175.000$. Falleció en la ciudad de Buenos Aires, el 8 de marzo de 1808. Antes de su muerte, el encargado de manejar la marcha de los negocios era su hijo mayor (Juan José), mientras que los hermanos menores se ocupaban de visitar a sus agentes comerciales en el interior.

La herencia que dejó su padre aumentó hasta los \$250.000 en 1811, momento en el cual sus herederos finalmente repartieron el activo, correspondiéndoles unos \$ 55.000 a cada uno de los tres hijos (Juan José, Tomás Manuel y Mariano Nicolás) y \$ 87.000 a la viuda. ${ }^{4}$ Ese año, Tomás Manuel emprendió un viaje al Alto Perú con intención de revisar los negocios de la familia y los suyos propios en medio de la convulsión provocada por la revolución y la llegada de las tropas enviadas desde Buenos Aires. Esos territorios no eran ajenos para él ya que en la Universidad de Chuquisaca había obtenido los títulos de Doctor en Teología y Abogado. Esos saberes, sumados a la posición privilegiada que ocupaba la familia en la élite porteña, le habían permitido desempeñarse como Regidor en el Cabildo de Buenos Aires entre 1807 y 1810 (Cutolo, 1968, T. I, p. 77). Una vez en el Alto Perú, Anchorena describía un panorama poco auspicioso con la llegada de los militares porteños, ya que eso había provocado

(...) el odio manifiesto de que se han poseído todas estas gentes contra nosotros. Ellas no desconocen la santidad y justicia [de la revolución] que hemos proclamado, pero maldicen la conducta de nuestras tropas culpando a los oficiales y jefes (...) Entretanto voy haciendo aquí [Sucre] diligencias de vender al contado lo que tengo en Potosí, pues no me determino a pasar a aquella villa (...) pues aún hay mucho riesgo por los soldados prófugos y desertores que andan por los caminos $(\ldots)^{5}$

Transitar esos territorios ya no era -como lo había sido para su padre y su hermano mayor- una promesa de negocios y acuerdos, sino que primaba la incertidumbre ligada al desarrollo de los enfrentamientos militares. Debido a ello, esperaba un tiempo "más sereno y menos peligroso" para poder acceder a sus mercaderías más preciadas colocadas en Potosí. ${ }^{6}$ El avance del ejército realista empujó a las tropas porteñas hasta Jujuy y con ellas a Anchorena que responsabilizaba a los soldados de los malos resultados a la vez que valoraba las medidas represivas tomadas por algunos mandos militares. En ese sentido, realzaba las figuras de Díaz Vélez y Dorrego, dado que "marcharon a Tupiza con 400 hombres armados, a pie y en el mejor orden",

(...) pues habiéndose descubierto una conspiración de los soldados contra los jefes (...) pasaron a dos por las armas en esta plaza y a la mañana siguiente hicieron lo mismo con otros cinco a dos leguas de distancia, con cuyo ejemplo (...) y las medidas que toma continuamente el General Pueyrredón, tienen en un puño a los soldados y van sujetando a los oficiales, de cuya anterior corrupción y desorden han provenido todas las desgracias $(. . .)^{7}$

En el mismo sentido, la llegada de Manuel Belgrano para ponerse al frente de las tropas, a mediados de 1812, le produjo un notable cambio de ánimo. En ese contexto, veía con esperanza y admiración las decisiones tomadas por el general, ya que

(...) ha puesto todo en orden y se ha merecido mucho respeto. Algunos lo consideran un déspota, pero yo no puedo decir nada sobre este particular ¡Ojalá sus antecesores hubieran observado su conducta! Nuestra situación en el día sería muy diferente $(. . .)^{8}$

La correspondencia de Anchorena muestra una preocupación creciente por los avatares del escenario bélico y el impacto que eso tenía en sus operaciones. Sus contactos con los militares que conocía de Buenos Aires le abrían algunas posibilidades ante las dificultades que atravesaba el comercio en un contexto donde el rechazo de los comerciantes locales se sumaba a la amenaza del avance español. ${ }^{9}$ Así, realizaba pequeños préstamos a algunos conocidos -como Manuel Dorrego ${ }^{10}$ - y esto le permitía resolver los problemas para enviar y recibir correspondencia utilizando el correo del ejército. Gracias a esos favores, obtenía la posibilidad de usar el único sistema de comunicación que, en ese contexto, resultaba relativamente seguro. En esas cartas, le recomendaba repetidamente a su hermano Mariano Nicolás en Buenos Aires que se mantuviera distante del 
poder político, ya que la situación "ha ocasionado mil facciones y partidos", y aunque "tú no eres bobo, solo quiero encarecerte el gran cuidado con que proceder en todo asunto público que se te ofrezca". ${ }^{11}$

Pocos meses después de ese impulso optimista, las tropas realistas avanzaban hacia el sur, tomaban Cochabamba, y, como consecuencia, Belgrano decidía iniciar el éxodo a Tucumán. La visión que sobre esa situación refería Tomás Anchorena era muy negativa, tanto sobre los negocios como sobre el futuro de la guerra: "yo no sé cómo será esto, cuando sobra gente y faltan armas..." ${ }^{12}$ Ese pesimismo lo llevó a negarse a un pedido hecho por Belgrano para oficiar como su Secretario debido a que "(...) esto me perjudicaría mucho en mis atenciones particulares y porque creo que las cosas no van como deberían ir (...)" ${ }^{\prime 3}$ Tan poco auspicioso era el escenario que le hacía pensar en la posibilidad de trasladarse a Chile, no obstante, el viaje se veía imposibilitado porque "no se hallan transportes, porque todos o los más están de cuenta del ejército (...) de modo que esta dificultad es la más insuperable”. ${ }^{14}$

Sin embargo, en noviembre le escribió a su familia para trasmitir que, pese a sus pronósticos, las órdenes de Belgrano habían provocado el éxito (en referencia a la batalla de Tucumán ocurrida a fines de septiembre). En ese momento decidió aceptar el ofrecimiento del cargo de Secretario del General, aunque “(...) el cargo me es demasiado molesto y casi insoportable, pero por lo que me ha expresado Belgrano, y yo he reflexionado, creo que le hago un servicio a la Patria [...] Conozco el perjuicio a que me expongo, y voy a experimentar (...)"15

Así, la precaución que repetidamente le suplicaba a su hermano Nicolás en Buenos Aires -para no aceptar cargos públicos-, era transgredida por él mismo ante la posibilidad de perder todas sus mercaderías en el Alto Perú. Desoyendo los consejos de su madre y su hermano menor para que regresara a Buenos Aires ${ }^{16}$, Tomás Manuel seguía adelante con una acción arriesgada que, a los pocos meses, se revelaría momentánea. Belgrano le inspiraba confianza en una guerra de resultado incierto y permanecer cerca suyo era su apuesta hasta que se aclarara el panorama.

En los primeros meses de 1813, con el resultado de la batalla de Salta, las oportunidades de Tomás Manuel se multiplicaron y su empleo en el ejército comenzó a ser una carga. Para desligarse de aquella ocupación, le escribía a su madre dándole los argumentos que ella debía utilizar en una futura misiva, solicitando su regreso a la capital:

Para este efecto le estimaré a Ud., me escriba una carta con fecha 1 del corriente [febrero] exigiéndome [...] regresar cuanto antes [...] y como si yo le hubiese contestado que tuviese paciencia, me escribe Ud. otra con fecha del 1 del que viene, estrechándome a que me apure a regresar y renuncie a mi empleo, pues Ud. se halla en edad avanzada, achacosa, que puede de un día a otro fallecer [...] a lo que puede Ud. agregar otras razones [...] para que yo me vea obligado a renunciar. ${ }^{17}$

Ante los buenos augurios, consideraba que su "servicio a la patria" había sido suficiente y decidía alejarse de Belgrano para avanzar finalmente hasta Potosí. Al llegar a su destino, lo invadió un cambio profundo en sus expectativas; allí constataba que la ciudad había "quedado arruinada" y no había lugar para los negocios. ${ }^{18}$ Sumado al estancamiento comercial que relataba, se mostraba cada vez más molesto con el accionar de los oficiales del ejército y le recomendaba a su hermano que cobrara todas las cuentas que pudiera con el Estado ya que "tú no sabes entre que gente estamos, como yo sé su interior para engañarte no te faltarían con buenas palabras [...] te vuelvo a decir que no seas sonso". ${ }^{19}$

Su mirada sobre los asuntos públicos se veía influenciada negativamente con el juicio sobre las personas que dirigían el proceso. Exceptuando a Belgrano y algunos otros -como Martín de Pueyrredón y Díaz Vélez-, culpaba al resto del estancamiento, ya que los comerciantes locales, "temerosos que les sucediese lo que con Castelli, y de un saqueo de esta chusma, se han ido con el enemigo" y, en ese marco, "los indios de mita no trabajan, no hay minería, no hay comercio, nadie viene a comprar, los de aquí solo aspiran a vender lo poco que tienen $(. . .)^{20}$ Estas mismas opiniones sobre los militares se agravarían unos meses más tarde con las derrotas de Vilcapugio y Ayohúma (octubre y noviembre de 1813), en las que “(...) ha sido un escándalo la cobardía y el atolondramiento de estos indecentes que solo sirven para intrigar." 21 
En sus cartas desde el norte se puede rastrear, además, indicios de sus posicionamientos posteriores. Frente a las derrotas militares sufridas, Anchorena planteaba la necesidad de que el Gobierno apostara al Alto Perú con todos sus recursos ya que vencer al enemigo en Lima allanaría el camino para el triunfo general. En este sentido, se manifestaba a favor del abandono de la Banda Oriental frente al avance portugués, debido a que

(...) es menester perder parte de las provincias ya que valen más en esta [Potosí] seis mil hombres que doce en esa [Buenos Aires], porque pueden acabar con el ejército de Lima, promover la revolución en aquel Virreynato, sostenerse con los recursos de estos países y resistir cualquier invasión de hacia abajo $(. . .)^{22}$

En 1814, Anchorena regresó a Buenos Aires con experiencia en el contacto directo con la guerra. En esos años había acumulado, además de pérdidas y desilusiones, algunas ideas sobre la marcha general de los hechos políticos. En primer lugar, culpaba a los militares cuya mala actuación había provocado divisiones innumerables y resquemores hacia adentro del bando patriota. En ese contexto, entendía que un liderazgo militar fuerte era la única posibilidad de conseguir un orden apropiado para que los negocios mejoraran. En Buenos Aires, la suma de facciones que luchaban por el poder no lo hacía conjeturar un futuro diferente ya que en esa lucha se involucraban otros sectores sociales y, por ello, lo mejor era mantenerse distante. A fines de 1814, se lamentaba por esta situación cuando le escribía a un socio en Jujuy y le confesaba que "ha de saber Ud. que este es el país de los bribones, que todos se han metido a políticos" y, por lo tanto, prefería mantenerse "encerrado en un rincón de $[\mathrm{su}]$ casa sin hacer negocios, pues veo que en el día se trabaja solo para perder". ${ }^{23}$ En ese escenario caótico, Anchorena entendía que la única posibilidad para conseguir el orden era que el gobierno concentrara los esfuerzos en el norte a fin de poder vencer a los realistas y avanzar hasta Lima, aunque para ello fuese necesario perder otras provincias.

Ese convencimiento lo llevó, en 1815, a volver al Alto Perú acompañando el avance de las tropas. El resultado sería similar a sus experiencias anteriores: a fines de 1815 se veía forzado a alejarse de Potosí por tercera vez- por el resultado de la batalla de Sipe Sipe. Nuevamente se asentaba en Tucumán, donde participaría de las reuniones del Congreso en representación de Buenos Aires.

\section{El Congreso de Tucumán: de la precaución a la disputa política}

Tras sus fracasos comerciales, Anchorena se encontraba desalentado y alejado de los negocios. A comienzos de 1816, se describía como "un hombre a quién lo tienen casi agoviado las desgracias (...)”. ${ }^{24}$ En ese marco, sus saberes y sus experiencias previas resultarían valiosos para formar parte del Congreso en San Miguel de Tucumán, cuya convocatoria se materializaba el 24 de marzo de 1816. Como bien explica Irurozqui (2016, p.163) todos los diputados (treinta y tres) eran licenciados o doctores en Artes, Teología y Derecho, y trece de ellos - como Anchorena- habían estudiado en la Universidad de San Francisco Javier. Si bien su distanciamiento del comercio no fue definitivo ${ }^{25}$, la intervención en el Congreso marcaría en Tomás Manuel una aproximación más decidida al poder político que tendría consecuencias en años posteriores. Los buenos augurios que había despertado la revolución se habían diluido y tanto él como su hermano mayor entendían que no se podía continuar al margen de las decisiones que impactaban en sus finanzas. ${ }^{26}$

Tras la declaración de Independencia, el Congreso retomó las discusiones sobre la forma de gobierno. En ese marco, Anchorena encabezó la oposición del proyecto que lograba mayor adhesión. Su admirado general Belgrano, para quien había trabajado años anteriores, proponía establecer una "monarquía temperada en la dinastía de los Incas y sus legítimos sucesores y como sede del gobierno a la ciudad de Cuzco". ${ }^{27}$ Este proyecto concitaba los apoyos de importantes figuras militares como Güemes y San Martín, y contaba con la aprobación de buena parte de los diputados de las provincias del norte (Souto, 2016, p. 6).

En ese marco, Anchorena fue el único que rechazó abiertamente el régimen monárquico argumentando sobre los inconvenientes que se derivarían de su adopción en un territorio con tantas variaciones culturales 
como el rioplatense. Frente a esto, el diputado porteño propuso una "federación de provincias" como medio para conciliar las diferencias geográficas y culturales presentes en el territorio rioplatense (Souto, 2016, p. 6). Años más tarde, en una carta a su primo Juan Manuel de Rosas, Tomás Manuel explicaba lo sucedido confesando que la propuesta de Belgrano había dejado "atónitos con lo ridículo y extravagancia de la idea" a los diputados de Buenos Aires y a algunos otros; aunque, con semejante adhesión, otros diputados optaron por "callar y disimular el sumo desprecio con que mirábamos tal pensamiento, quedando al mismo tiempo admirados de que hubiese salido de boca del general Belgrano" (Souto, 2016, p. 6). También aclaraba que su rechazo no era por el régimen monárquico constitucional sino por la idea de que el trono fuera ocupado por "un monarca de la casta de los chocolates, cuya persona, si existía, probablemente tendríamos que sacarla borracha y cubierta de andrajos de alguna chichería". 28

En su examen de los debates sobre la forma de gobierno, Nora Souto destaca las instrucciones a las que los diputados debían atenerse. En cuanto a los de Buenos Aires, su mandato era por la "indivisibilidad del Estado". Como destaca la autora, en aquel contexto, esa noción se vinculaba directamente con la posibilidad de una monarquía temperada o constitucional. La principal causa del repudio de los diputados bonaerenses parecería originarse más bien en la intención de trasladar la capital al Cuzco, medida que condenaría a Buenos Aires y su élite a perder la dirección del gobierno y su calidad de centro de gravedad político. En ese marco, para los diputados porteños la idea de unidad era inseparable de la conservación de la preeminencia de la ciudad puerto (Souto, 2016, p. 7). Como se observa, la llegada al escenario político podía conllevar muchos riesgos pero, al mismo tiempo, daba lugar a intervenir en pos de proteger los beneficios que podían reportar los negocios si el orden finalmente se lograba. Luego de una primera etapa, donde la recomendación a su hermano menor era la de mantenerse lo más alejado posible de los que "se han metido a políticos", Anchorena intervenía haciendo gala de un perfil alto, oponiéndose al proyecto de Belgrano en defensa de sus intereses.

A riesgo de caer en interpretaciones que ubican a los actores en facciones determinadas, resulta más sugerente evaluar sus intervenciones en los diferentes contextos. Así, puede notarse una primacía de cierto pragmatismo político donde lo primordial resultaba encontrar soluciones provisorias para los problemas que acuciaban. En este sentido, puede entenderse la oposición de Tomás Anchorena al proyecto de Belgrano, no como una impugnación a la monarquía per se, sino más bien una forma de desacreditar un proyecto que afectaba los intereses de Buenos Aires más allá del coronamiento de un inca. El debate sobre la monarquía incaica concluyó sin que se arribara a un consenso y la cuestión no volvió a retomarse en las sesiones públicas de los años siguientes. Sin embargo, las sesiones secretas y las tratativas llevadas a cabo por comisionados del gobierno directorial (de las que participó el propio Anchorena), tanto en Brasil como en Europa, muestran que los proyectos de coronar a un príncipe para el Río de la Plata estuvieron lejos de archivarse. ${ }^{29}$ Justamente las negociaciones entre el Directorio y la corte portuguesa serían el arma elegida por el gobernador Sarratea en 1820 para encarar los juicios por Alta Traición contra los que habían integrado ese gobierno. De este modo, los riesgos de intervenir en política sobre los que tanto advertía a su hermano se iban a ver cristalizados en su propia experiencia durante 1820 .

\section{El ingreso a la SALA de Representantes y los Juicios a los miembros del Directorio}

La Constitución sancionada en 1819 fue calificada por Bartolomé Mitre, décadas después, como la obra de una "minoría ilustrada, racional, iluminista, centralista y monárquica, [...] que era revolucionaria por su origen, pero reaccionaria por sus ideas" (Mitre, 1947, p. 47). Este juicio se fundaba en las resistencias que provocó la carta magna, articulando el rechazo de los opositores porteños de Pueyrredón con los reclamos de las fuerzas federales del litoral. Las negociaciones con la corte portuguesa y la inacción frente a la invasión en la Banda Oriental completaron el cuadro. En ese marco, se produjo la batalla de Cepeda (febrero de 1820), la renuncia de José Rondeau -Director Supremo en reemplazo de Pueyrredón y comandante de las 
tropas derrotadas por las de Francisco Ramírez y Estanislao López-y la asunción del mando en Buenos Aires por parte del Cabildo. Dicha corporación había apoyado las iniciativas directoriales, por lo tanto, Ramírez y López exigían la formación de un nuevo gobierno a través de un Cabildo Abierto. ${ }^{30}$ Tras los sucesivos rechazos por parte de los caudillos litoraleños para pactar la paz con quienes habían sido parte de la "anterior administración”, la situación de Anchorena (y junto con él la de muchos otros) entraba en tensión a esperas de encontrar una salida para la apremiante realidad. Si bien su participación como diputado en el Congreso representando a Buenos Aires podía no ser considerada una intervención directa en el gobierno depuesto, no sucedía lo mismo con las negociaciones llevadas a cabo con la Corte luso-brasileña, ya que en esa acción se resumía el principal argumento de los federales: Pueyrredón y sus seguidores habían traicionado a la Revolución.

El Cabildo Abierto se convocó para el 16 de febrero. Allí emergió la opinión de Victorio García de Zúñiga (suegro de Anchorena): los 182 presentes en la asamblea votarían por dos candidatos y aquellos $12^{31}$ que consiguieran más votos serían los integrantes de una nueva Junta de Representantes encargada, en primer término, de elegir a un Gobernador que fuese aceptado por López y Ramírez para negociar la paz. ${ }^{32}$ Para que esta reunión pudiera concretarse, se firmaba un armisticio por tres días entre el General Soler (en representación de Buenos Aires) y los generales del ejército federal en Luján. ${ }^{33}$

Tomás Manuel Anchorena y su hermano Juan José conseguían los votos necesarios para integrar la nueva Sala de Representantes. La flamante institución optaba por erigir a un gobernador provisorio con una trayectoria previa que le brindaba más oportunidades de llegar a un entendimiento con los caudillos litoraleños: Manuel de Sarratea. ${ }^{34}$ No obstante, el equilibrio de poder entre el Gobernador y la Sala era débil. Entre sus miembros aparecían varios que, con trayectorias variadas, habían tenido participaciones en el Directorio. El caso de Tomás Manuel ilustra esta circunstancia ya que fue ese pasado el que determinó parte de su recorrido en la Sala. Allí, sus prevenciones sobre inmiscuirse en la política -trasmitidas a su hermano menor desde el norte- encontrarían un correlato en los hechos.

Las renuncias de varios de los Representantes aparecían a los pocos días de ser nombrados y los motivos se vinculaban a que los caudillos federales tenían, en ese contexto, la correlación de fuerzas inclinada a su favor y podían objetar sus designaciones. Así, Juan Pedro Aguirre, Juan José Paso y Vicente Echevarría hacían efectivas sus renuncias dos días después "por las tachas que les opusieron los jefes del Ejército Federal" (Levene, 1932, p. XXIII). En ese escenario, la pertenencia al gobierno caído determinaba la imposibilidad de integrar el nuevo cuerpo y el riesgo de enfrentar futuras acusaciones. ${ }^{35}$

A partir de ese momento, quien firmaba las actas como Presidente de la Sala era Tomás Manuel Anchorena. ${ }^{36}$ No obstante, esta situación se mantuvo pocos días ya que el 4 de marzo la Sala se reunió para hacer frente a estas circunstancias que resultaban agravadas por nuevas renuncias, entre ellas la del propio Tomás Anchorena. ${ }^{37}$ Como solución, la Sala acordaba que debería hacerse efectivo un nuevo llamado a elecciones de representantes para reemplazar a los dimitidos. En ese Acuerdo aparecían ampliadas las funciones de la futura Sala, anunciando una forma similar a lo que sería la Legislatura posterior: debería "establecer la forma de gobierno, confirmar al Gobernador y Cabildo electo o elegir otros, dictar leyes y entender en materia de tratados o negociaciones con las otras provincias" (Levene, 1932, p. XXIII). En estas circunstancias, si bien puede vislumbrarse un quiebre político entre Sarratea y los representantes, ¿̨por qué Tomás Manuel decidía renunciar y su hermano permanecía en la Sala? ¿Por qué abandonar la Sala si desde allí podía contrapesarse su poder u obstaculizar sus decisiones?

La principal causa de la renuncia se fundaba en la posibilidad de ser juzgado. Los reclamos de los caudillos federales en cuanto a que el nuevo gobierno no podía ser integrado por miembros del Directorio habían quedado plasmados en el acuerdo de paz. En el Artículo $7^{\circ}$ del Tratado del Pilar, firmado el 23 de febrero por López, Ramírez y Sarratea -y ratificado por la Junta de Representantes-, el Gobernador de Buenos Aires se comprometía, entre otras acciones, a iniciar los procesos judiciales contra los miembros de la anterior 
administración. ${ }^{38}$ Si bien la renuncia a la Sala no eximía a Anchorena de la posibilidad de ser sometido a juicio, le brindaba la oportunidad de salir del gobierno y esperar que las circunstancias se calmaran. Resultaba más riesgoso permanecer dentro de una Sala que intentaba una oposición al Gobernador apoyado por Ramírez y López. Aunque había renunciado, Tomás Manuel seguía contando con su hermano, su suegro y su socio y concuñado- Sebastián Lezica dentro del grupo que permanecía activo en la Sala, con lo cual, una iniciativa judicial de Sarratea podría ser obstaculizada de ese ámbito.

El 6 de marzo, dos días después de tratarse en la Sala la problemática de la escasez de miembros ante las renuncias más arriba detalladas, el General Balcarce se hacía del gobierno tras llevarse a cabo algunas protestas en la ciudad contra las decisiones de Sarratea y sus negociaciones con los jefes federales. ${ }^{39}$ El Cabildo se hacía eco del pedido popular separando del cargo al Gobernador, aunque se aclaraba expresamente que la Sala de Representantes no participaba del nombramiento ya que se hallaba "incompleta” y la elección se hacía por "votos individuales de todos los Ciudadanos" que deberían "prestarlos por propia voz ante el mismo Ayuntamiento" (Levene, 1932, pp. XXVIII-XIX).

Transcurridos pocos días, y por intervención de Ramírez y Soler, Sarratea fue repuesto en el cargo (el 11 de marzo) y, en ese marco proclamó -como respuesta al intento de derrocarlo- la implementación de los juicios por alta traición a los ex-miembros del Congreso y Directorio, como se había comprometido en el Tratado del Pilar. ${ }^{40} \mathrm{Al}$ mismo tiempo, para nombrar una nueva Junta -ya que la anterior quedaba imposibilitada de continuar por la escasez de miembros- se convocaba a elecciones en la ciudad y la campaña. En esta nueva Sala aparecían los mismos integrantes que en la anterior, con algunos mínimos cambios. Así, las elecciones habían sido una derrota política para el Gobernador quien, tras ser restaurado, se encontraba en una posición bastante debilitada ya que Ramírez -su respaldo militar- volvía a Entre Ríos porque le era disputado (Halperin Donghi, 2005, p. 347; Herrero, 1999, p. 122).

En este nuevo escenario, Tomás Anchorena aparecía como una figura de suma importancia ya que la cantidad de votos que su candidatura recolectaba (luego de haber renunciado cuando ejercía el cargo de Presidente de la Sala) superaba ampliamente al resto: 212 votos; más de 30 lo separaban del segundo candidato más votado. ${ }^{41}$ Como respuesta, Sarratea jugaría la carta de los procesos judiciales. Ni bien concluida la elección, el Gobernador inhibía la participación de cuatro de los elegidos: J. J. Paso, J. P. Aguirre, V. López y Planes y T. Anchorena. El 28 de abril Sarratea aclaraba ante la Sala las causales de la separación: Aguirre estaba acusado de haber facilitado la evasión de Pueyrredón; López y Planes de haber sido Secretario durante su directorio; Paso y Anchorena de haber negociado con los portugueses una solución monárquica durante 1819 (Levene, 1932, p. LVI). ${ }^{42}$

El Gobernador acudía al Cabildo para que resolviera sobre los representantes vetados ya que era de esperar que la Sala no hiciera lugar a esa decisión. En ese marco, la discusión pivoteaba sobre una cuestión fundamental: las atribuciones del gobernador para implementar procesos judiciales. Sarratea se sustentaba en que la anterior Junta había dispuesto que los ciudadanos sometidos a procesos judiciales quedaban imposibilitados de integrarla. Por lo tanto, aseguraba, "el pueblo no pudo ni debió votar por ellos [...] porque la libertad de votar no es absoluta sino reglada y sujeta a disposiciones y a ellas deben subordinarse todos" (Levene, 1932, p. LVIII). Ante la inacción del Cabildo, el Gobernador decidía poner en prisión a los electos vetados. Como respuesta, Tomás Manuel Anchorena publicaba su Excusación donde se defendía de las acusaciones a la vez que encaraba una feroz crítica hacia Sarratea, ya que éste

(...) hace de Gobernador, de magistrado ordinario de justicia, de juez de residencia, de legislador [...] pone en prisión a ciudadanos [...] se presenta con mas autoridad que el mismo Ser Supremo, al paso que á todas horas se le oye propalar liberalidad, justicia, imparcialidad [...] aunque con la desgracia, á mi ver, de que nadie le cree, y de que son muy pocos los miserables que afectan creerle (Anchorena, 1820, p. 1).

A pesar de haber remarcado, pocos años antes, la necesidad de actuar con cautela en los asuntos políticos, Anchorena se encontraba nuevamente en el centro de una disputa que, a diferencia de lo ocurrido en el 
Congreso de Tucumán, ponía en riesgo su honor y su libertad. En ese marco, se preguntaba "si en un orden liberal [...] cabe que un Gobernador reúna semejantes facultades"; sobre todo, teniendo en cuenta que éstas estaban en manos de aquel que, "habiendo ido de General a la Banda Oriental, es considerado autor principal del rompimiento obstinado del General Artigas con el Gobierno de las Provincias Unidas" (Anchorena, 1820 , p. 1). En lo relativo a las negociaciones con la corte portuguesa, Anchorena también recurría al pasado para defenderse y resaltaba que

(...) como encargado de las relaciones exteriores con las cortes de Europa, Sarratea trató de restablecer la dinastía de los Borbones ingiriendo al Conde de Covarrús en este negocio, y que habiendo consumido al estado ingentes miles [...], jamás hizo cosa alguna que mereciese nuestra atención [...] Sabemos que [...] mejor que las relaciones del Brasil, deberían publicarse las del Sr. Sarratea cerca de la persona de nuestro viejo rey (...)(Anchorena, 1820, p. 2)

Así, a la vez que cuestionaba la legitimidad de los procesos planteados por el Gobernador lo atacaba y denunciaba. Estas denuncias iban dirigidas debilitar los apoyos que Sarratea concitaba, sobre todo, entre los federalistas porteños. Por una parte, lo responsabilizaba por el origen del enfrentamiento entre Buenos Aires y Artigas y, por la otra, lo sindicaba como protagonista de tratativas monárquicas con la dinastía que más resentimiento generaba en el público. La cuestión terminaría de ser definida dentro de la propia Sala que ya mostraba una marcada transformación: dejaba de ser una simple asamblea electoral de segundo grado encargada de designar al gobernador para intentar convertirse en un cuerpo que buscaba ocupar el centro de la escena política provincial (Ternavasio, 2002, p. 59). En ese marco, el Gobernador aceptaba dicha primacía cuando juraba por los Santos Evangelios y prometía "a la Patria" reconocer la soberanía de la Provincia en la Junta de Representantes, "obedeciendo y haciendo executar todas las órdenes y demás resoluciones que emanen de ella". ${ }^{3}$

La contradicción se hizo evidente: la primera disposición de la Sala fue el ingreso de los cuatro representantes vetados, por lo que Sarratea debía disponer su inmediata libertad remitiendo los procesos a la Legislatura, ya que ésta nombraría una comisión encargada de revisarlos. La oposición era rematada al momento de la votación para confirmar o reemplazar al primer mandatario. El resultado fue abrumador: Sarratea fue desplazado ya que la Sala "se inclinó quasi entera o bien en aclamación a la persona de D. Ildefonso Ramos Mexía”. 44

Una vez corrido Sarratea, los representantes trataron los casos de dos de los procesados: Tomás Anchorena y J. J. Paso. En este punto -aclara el Acuerdo- se debió recurrir al reglamento del Cabildo (para evitar las interrupciones) debido a que la discusión se "entretegió y ramificó tanto que acalorada en términos acaso fastidiosos”. Al parecer, si bien existía consenso en desplazar a Sarratea, no sucedía lo mismo con las acciones relativas a los juicios comenzados por aquel. En un contexto donde las fuerzas del litoral aún continuaban siendo una amenaza, desconocer los términos del Tratado del Pilar implicaba un riesgo demasiado grande. Finalmente se acordó que, hasta la creación de una "autoridad nacional suprema", se sobreseyese a los acusados. Luego, al considerar si estos representantes (T. Anchorena y J. J. Paso) podían reincorporarse a la Sala, la mayoría acordó que lo mejor sería "la pronta subrogación" por aquellos que, en la última votación, habían reunido más votos. En este marco, el lugar de Tomás Manuel sería ocupado por aquel al que repetidas veces había advertido de no mezclarse con la política: su hermano menor Mariano Nicolás. Tomás Manuel Anchorena se asentaría en la Banda Oriental por espacio de una década y regresó a Buenos Aires para formar parte del gabinete de su primo, Juan Manuel de Rosas.

\section{CONSIDERACIONES FINALES}

La crisis política desatada en Buenos Aires a partir de 1820 y la profunda politización experimentada en los años anteriores llevó a los miembros de la élite a intervenir para buscar soluciones en un marco apremiante. La Sala de Representantes surgió así como respuesta a las intimaciones de los jefes del ejército federal triunfante en Cepeda. Entre otros requerimientos, el nuevo gobierno no podía estar integrado 
por miembros de la anterior administración, lo que hizo que figuras con recorridos variados y disímiles aparecieran dentro del nuevo cuerpo que buscaba legitimarse como representación de la provincia.

En este trabajo, se exploraron algunos aspectos de la trayectoria de un miembro de la élite porteña que, ubicado entre los más ricos comerciantes, se vio empujado a acercarse al poder político a lo largo de la década de 1810, tras advertir las consecuencias negativas que la revolución y la guerra habían provocado en la economía. Asimismo, resulta relevante reconstruir su recorrido repasando sus impresiones sobre los acontecimientos y sus valoraciones sobre la politización desatada a partir de 1810. En este sentido, Anchorena se manifiesta como un convencido de la causa revolucionaria y responsabiliza a algunos militares por las derrotas sufridas en el Alto Perú. La primera parte de su recorrido en el norte deja entrever un temprano entusiasmo que se va transformando paulatinamente en desesperanza. Aquí también se remarcaron las vinculaciones directas que existían entre la esfera comercial, la militar y la política. Una vez desatado el proceso revolucionario y los vaivenes de la guerra, Anchorena entendió (y como él tantos otros) que se había vuelto ineludible intervenir en la política para no dejar todo en manos de aquellos "bribones" culpables de las "mil facciones". Así, su participación era trasmitida a su familia como un mal necesario cuyo objetivo final era, de todas formas, aportar a resolver los acuciantes problemas para retomar la senda exitosa de los negocios. De esta forma, resultan comprensibles algunas de sus decisiones, como la aceptación del ofrecimiento de Belgrano seguida por la pronta intención de desligarse de ese cargo una vez que el escenario bélico mejoró sus expectativas.

Su oposición al proyecto de establecer una monarquía incaica en 1816 fue analizada a partir de lo que, en términos económicos, implicaba que Buenos Aires dejara de ser la ciudad capital. En este sentido, sostenemos que la pertenencia de Anchorena a determinado grupo o facción política se vio matizada por estas explicaciones que encuentran espacio en una perspectiva que apunta a mostrar cómo "se expresa la singularidad de su posición en el interior de la clase o grupo (...)” (Bourdieu, 1997, p. 75). Si bien se manifestó contrario a la monarquía en esa oportunidad, poco tiempo después se encontraría negociando una salida monárquica con la Corte luso- brasileña. Esa segunda etapa, donde Anchorena se acercó de lleno a la disputa política, dejó huellas que resultaron determinantes en su actuación como representante del pueblo de Buenos Aires en un organismo colegiado creado en medio de la crisis de 1820. Así, tras ser vetado y puesto en prisión por el gobernador para integrar la flamante Sala de Representantes, Anchorena retomó el guante de la disputa política y puso en juego, tanto sus saberes jurídicos, como sus experiencias previas y vinculaciones. De esa forma, el ataque emprendido por Sarratea (e instigado por las exigencias de Ramírez y López) contra los que habían sido parte del gobierno directorial, se transformó en una contienda entre la Sala y el Gobernador, que finalizó con el segundo derrotado y con la primera consagrada como un ámbito de poder decisivo, de ahí en adelante, en el tablero de la política bonaerense.

\section{ReFERENCiAS}

Anchorena, T. M. de (1820). Excusación de D. Tomás Manuel de Anchorena del empleo de Representante de la Provincia para el que le nombró el pueblo. Buenos Aires: Imprenta de Álvarez. Recuperado de: https://archive .org/details/excusaciondedtom00buen

Bourdieu, P. (1997). “La ilusión biográfica”. En P. Bourdieu. Razones prácticas. Sobre la teoría de la acción, Barcelona: Editorial Anagrama, pp. 74-83.

Carretero, A. M. (1970). Los Anchorena. Politica y negocios en el Siglo XIX. Buenos Aires: Ediciones 8va Década.

Cutolo, V. (1968). Nuevo diccionario biográfico argentino (1776-1930). 7 Tomos. Buenos Aires: Elche.

Di Meglio, G. (2003). "La consolidación de un actor político: los miembros de la plebe porteña y los conflictos de 1820". En H. Sábato y A. Lettieri (comp.). La vida politica en la Argentina del siglo XIX. Armas, votos y voces. Buenos Aires: F.C.E., pp. 173-189. 
Di Pasquale, M. y M. Summo (2015). "Las trayectorias intelectuales como problema”. En M. Di Pasquale y M. Summo (comp.). Trayectorias singulares, voces plurales: intelectuales en Argentina, siglos XIX-XX. Buenos Aires: EDUNTREF, pp. 11-20.

Fitoussi, J. y P. Rosanvallon (1997). La nueva era de las desigualdades. Buenos Aires: Manantial.

Herrero, F. (1999). “Indicios y estrategias. Luchas por el poder en Buenos Aires durante el crítico año de 1820”. En Probistoria, N. 3, pp. 111-132.

Herrero, F. (2010). "Un gobierno federal", "liberal y de principios”. La experiencia del gobierno de Manuel Sarratea durante el crítico año de 1820”. En Andes, Vol. 21, núm. 2.

Hora, R. (2006). "Patrones de inversión y negocios en Buenos Aires en la primera mitad del siglo XIX: la trayectoria de Tomás Manuel de Anchorena”. En História econômica \& história de empresas, Vol. 8, No. 1.

Hora, R. (2010). "Los Anchorena: patrones de inversión, fortuna y negocios (1760-1950)". En América Latina en la Historia Económica, núm. 37.

Irurozqui, M. (2016). “La telaraña de los Doctores. Charcas en el Congreso de Tucumán de 1816”. En Prismas, Univ. Nac. de Quilmes, vol. 20, núm. 2, pp. 153-160.

Kraselsky, J. (2011). “Las estrategias de los actores del Río de la Plata: Las juntas y el Consulado de Comercio de Buenos Aires a fines del Antiguo Régimen 1748-1809”. Tesis de posgrado, Universidad Nacional De La Plata. Facultad de Humanidades y Ciencias de la Educación.

Levene, R. (1932). "La anarquía del año 1820 en Buenos Aires desde el punto de vista institucional”. En Acuerdos de la Honorable Junta de Representantes de la Provincia de Buenos Aires (1820-1821). La Plata: Publicaciones del Archivo Histórico de la Provincia de Buenos Aires, Tomo V, Volumen I, Año 1820.

Levi, G. (1989). “Los usos de la biografía”. En Annales, núm. 6, pp. 1325-1336. Traducción de Araceli Rodríguez Tomp.

Milletich, V. (2006). "La formación del capital de un comerciante porteño: Juan Esteban de Anchorena, 1750-1775”. En Anuario IEHS, 21.

Mitre, B. (1947). Historia de Belgrano y de la Independencia argentina. Buenos Aires: Estrada.

Polastrelli, I. (2017). “Castigar los crímenes de la anterior administración”. El juicio contra los miembros del Directorio y del Congreso en 1820”. En Anuario del Instituto de Historia Argentina, Núm. 17(2).

Olivero, S. (2010). "Estrategias de formación y consolidación de las familias de elite comercial y política porteñas". En G. Levi (ed. Lit.) y R. Rodríguez Pérez (comp.). Familias, jerarquización y movilidad social. Univ. de Murcia, pp. 87-101.

Saldías, A. (1919). La evolución republicana durante la revolución argentina. Madrid: América.

Sarratea, M. de (1820). Proceso original justificativo contra los reos acusados de Alta Traición en el Congreso y Directorio por el artículo séptimo del Tratado de paz firmado por este Gobierno con los Gefes de las fuerzas federales de Santa Fe y La Banda Oriental. Buenos Aires: Imprenta de Álvarez, 14 de marzo de 1820.

Souto, N. (2016). "La idea de unidad en tiempos del Congreso de 1816-1819”. En Anuario del Instituto de Historia Argentina, Núm. 16 (1).

Ternavasio, M. (2002). La revolución del voto: politica y elecciones en Buenos Aires, 1810-1852. Buenos Aires: Siglo XXI.

\section{Notas}

1 Los tres apartados de este artículo exploran registros diferentes. Esto se debe a la disponibilidad de fuentes primarias en el Archivo General de la Nación. Al respecto, fueron consultados los legajos 313, 329 y 331 del Fondo J. E. Anchorena (Sala VII). Mientras que para el período 1810-1814 se encuentra una correspondencia nutrida con sus hermanos, su madre y algunos socios comerciales, no sucede lo mismo con los años posteriores. Las cartas enviadas o recibidas por él resultan esporádicas y hacen referencia, sobre todo, a sus tratos comerciales. En este sentido, sus intervenciones en el Congreso de Tucumán y en la Sala de Representantes de Buenos Aires son analizadas a través de fuentes secundarias y de los documentos oficiales emanados de dichas asambleas.

2 Respecto de las estrategias de matrimonio entre familias de comerciantes, véase Olivero (2010). 
3 Para un estudio exhaustivo de las estrategias llevadas adelante por los miembros del Consulado de Comercio, véase Kraselsky (2011).

4 Para un estudio exhaustivo de la evolución de los negocios de la familia, véase Hora (2010). El autor destaca que esa fortuna solo era superada, en el Río de la Plata, por unos pocos comerciantes, entre los que se destacaban Segurola, Domingo Belgrano y Francisco Tellechea, que legaron entre 300000 y 400000 pesos. La diferencia es que estos comerciantes dividieron su patrimonio en un elevado número de descendientes mientras que a Juan Esteban Anchorena sólo le sobrevivieron tres hijos de siete.

5 T. M. Anchorena a Juan José Cristóbal Anchorena, 10 de agosto de 1811, en A.G.N, Sala VII-313, citada por Carretero (1970), p. 21.

6 Ídem.

7 T. M. Anchorena a Mariano Nicolás Anchorena, 4 de diciembre de 1811, en A.G.N, Sala VII-313.

8 Ibíd., 18 de abril de 1812.

9 Ibíd., 10 de marzo de 1812.

10 Ibíd., 4 de febrero de 1812.

11 Ídem.

12 Ibíd., 18 de agosto de 1812, citada por Carretero (1970), p. 34.

13 Ídem.

14 Ídem.

15 Ibíd., 12 de noviembre de 1812, citada por Carretero (1970), p. 36.

16 Nicolás Anchorena a T. M. Anchorena, 19 de diciembre de 1812, en A.G.N, sala VII-313.

17 T. M. Anchorena a Romana López de Anaya, 27 de febrero de 1813, en A.G.N, Sala VII-313.

18 T. M. Anchorena a Mariano Nicolás Anchorena, mayo de 1813, en A.G.N, Sala VII-313.

19 Ibíd., 27 de junio de 1813, citada por Carretero (1970), p. 41.

20 Ibíd., mayo de 1813, citada por Carretero (1970), p. 40.

21 Ibíd., 18 de diciembre de 1813, citada por Carretero (1970), p. 50.

22 Ibíd., 8 de octubre de 1813, citada por Carretero (1970), p. 47.

23 T. M. Anchorena a Teodoro Sánchez de Bustamante, 26 de noviembre de 1814, en A.G.N, Sala VII-313, citada por Hora (2010), p. 56.

24 T. M. Anchorena a Vicente Echevarría, 17 de enero de 1816, en A.G.N., Sala VII-313, citada por Hora (2010), p. 57.

$25 \mathrm{Al}$ respecto, véase Hora (2010), p. 58. El autor destaca que se dio un cambio de rumbo en sus actividades comerciales, inclinándose al acopio y venta de cueros.

26 Sobre la intervención de Juan José Anchorena en Buenos Aires, véase Carretero (1970), pp. 98-14.

27 Sesión del 12 de julio de 1816 (Ravignani, 1937-1939, I: 236), citado por Souto (2016), p. 5.

28 T. M. Anchorena a Rosas, 4 de diciembre de 1846, en Saldías (1919), pp. 303-304, citado por Souto (2016), p. 6.

29 Entre los candidatos europeos propuestos estaban el Duque de Orleans y del Príncipe de Luca; por su parte, las negociaciones con el Imperio del Brasil pautadas por instrucciones reservadas y reservadísimas, barajaron la unión matrimonial de un descendiente de los Incas con un miembro de la dinastía Braganza y en el hipotético caso de que se exigiera la incorporación de las Provincias Unidas al Imperio del Brasil autorizaron al enviado para avanzar en esa línea. Véase Souto (2016).

30 Quedaba expresa la desconfianza de Ramírez en la nota que enviaba al Cabildo donde manifestaba que "(...) de ningún modo prometí la detención de mis marchas ni dejar de ocupar aquellos puntos [de Buenos Aires] que conviniesen a la comodidad de mis tropas [...] He provocado a la paz por humanidad, por deber, por patriotismo [...] Es preciso que antes veamos cesar las aspiraciones de esa administración y que la que le suceda sea elegida por la voluntad general de la provincia en completa libertad." Véase “Oficio del Sr. General del ejército federal al del ejército exterior”. En Gaceta de Buenos Aires, 16 de febrero de 1820, en Junta de Historia y Numismática Argentina, T. VI, Buenos Aires, Compañía Sud-Americana de Billetes de Banco, 1915, p. 707.

31 Respecto de este número, Ternavasio (2002, p. 38) aclara que se había originado en las innovaciones introducidas por el Estatuto Provisional de 1815, cuyo criterio vinculaba la cantidad de representantes con el número de habitantes de cada jurisdicción.

32 La principal dificultad radicaba en que los jefes federales se negaban a pactar la paz con una figura identificada con el centralismo. Al mismo tiempo, aquellos que habían integrado el Directorio no podían dejar todo en manos de los federalistas porteños ya que peligraban sus intereses. La solución encontrada fue la formación de una Junta con mayoría centralista que, a su vez, nombraría a un Gobernador provisorio identificado con la oposición al directorio de Pueyrredón para que sí fuese aceptado como interlocutor por los litoraleños. Para profundizar este contexto, véase Herrero (2010).

33 Armisticio que ha celebrado el General Soler con los Gefes de la Fuerza Federal, citado por Levene (1932), p. XIV.

34 Sarratea, también comerciante, se diferenciaba de los Anchorena por su trayectoria política previa. Había sido opositor al directorio de Pueyrredón y fue enjuiciado por encabezar una sublevación contra él. En este sentido, la elección para 
Gobernador ha sido interpretada como una concesión a la facción anti-directorial de Buenos Aires. Véase Herrero (1999). Además, según refiere Cutolo (1968, T. VI, p. 727), Sarratea mantenía buenas relaciones con Ramírez y Carrera, que hacía un tiempo acompañaba al entrerriano.

35 Herrero (2010, p. 267) sugiere que la iniciativa de llevar a juicio a los "directoriales" habría sido impulsada por el propio Sarratea, quien en una carta a Miguel Carrera sostenía que "los más perversos del Congreso, Milicia, estado civil o eclesiástico, son conocidos de todos. Presidir este asunto sería la obra más delicada (hablo de la secuela de un juicio) y exige persona de probidad (...)".

36 El 19 de febrero la Sala elegía a los integrantes del nuevo Cabildo y esa acta ya no contaba con la firma de los tres renunciados. Acuerdos de la Honorable Junta de Representantes de Buenos Aires (en adelante AHJRBA, 1932), La Plata, Publicaciones del Archivo Histórico de la Provincia de Buenos Aires, p. 17.

37 Véase AHJRBA (1932) p. 25.

38 Véase AHJRBA (1932), pp. 19-22.

39 Habría sido importante para conseguir los apoyos al movimiento de Balcarce, dar a conocer cláusulas secretas del Tratado de paz donde Sarratea se comprometía a entregar armas y “otros auxilios”. Véase Levene (1932), pp. XXVI-XXXIII.

40 Véase Sarratea, M. de (1820).

41 Véase AHJRBA (1932), p. 36.

42 Para una profundización en el análisis de estos procesos judiciales, véase Polastrelli (2017).

43 AHJRBA (1932), p. 44.

44 Ibíd., p. 42. 